\title{
The Development, Characteristics and Impact of Bike- Sharing Systems:
}

\author{
A Literature Review
}

\author{
Lingwei Zheng ${ }^{1}$ and $\mathrm{Yan} \mathrm{Li}^{1 *}$ \\ 1 Colledge of Asia Pacific Studies, Ritsumeikan Asia Pacific University \\ * Corresponding Author, Email: yanli@apu.ac.jp
}

Received: March 18, 2019 Accepted: October 3, 2019

Keywords: Bike-sharing, assessment, literature review

Abstract: Bicycle sharing systems (BSSs) have attracted worldwide attention as representatives of the new, green public transportation systems, and many types of research have examined the topic. However, the research so far is relatively scattered, because BSS has undergone several technical upgrades and expansions, and the content of some articles may no longer apply to today's society. Therefore, it is necessary to review and summarise the research on BSSs so far. This article aims to collect and summarise the development, characteristics, and impact of BSSs through an extensive review of relevant literature. The article collects and analyses existing academic literature, online materials, and official reports. It is found that BSSs attract people with the same characteristics, and Western and Eastern users have different characteristics; some common factors promote people's use of BSSs in different regions. The government or enterprises introduce BSSs for different purposes: for reducing congestion or for reducing greenhouse gas emissions. Most of the impacts caused by BSSs are positive, but some impacts, such as model substitution and environmental benefits, do not seem to achieve the expected goals. Through a literature review, this article provides references for people who are interested in conducting further research in this area in the future.

\section{INTRODUCTION}

In the past decade, "bike-sharing" has taken many forms, from bike rentals managed manually by staff, to free bicycle distribution throughout the community. Today we can see more advanced and safer support systems. However, the purpose of bike-sharing systems has not changed: to enable users to get a bike in one spot and, after using, return it somewhere else.

Many urban infrastructures have been built and extended for vehicle travel, and these actions have caused various environmental problems. As a tool of green transportation, as well as an essential complement to public transportation and carpooling services, bike-sharing systems (BSSs) play an essential role in helping people achieve car-free living and the reduction of environmental pollution. Many effective transportation systems - for example, those in North America and China - have advanced bikes as a reasonable and important transportation choice. 
In the previous five years, the development of worldwide BSSs has been extensive. In 2016, there were more than 1,600 public and privately-operated station-based, dockless, and hybrid bike-sharing systems in operation, compared to just over 700 in 2013 (Chen, 2016). Recognising the opportunities offered by bike-sharing, cities are launching more advanced systems to help travellers avoid private vehicles, to accomplish climate, wellbeing and financial goals.

\section{METHODOLOGY}

This paper aims to critically explain the development, characteristics and impact of BBSs via an extensive review of relevant literature. The author mainly uses three data sources, as described below:

1) Rules and manuals for bike-sharing tasks. More specifically, the handbook created by the EU-subsidized project 'Optimizing bike-sharing in European cities' (OBIS (Optimising Bike Sharing in European Cities) 2011) and the bike-sharing planning guide provided by the Institute for Transportation and Development Policy (Institute for Transportation Development Policy, 2013). These two handbooks provide very comprehensive information about bike-sharing systems in Europe and North America and offer excellent guidelines for future applications.

2) Websites, including websites for sharing bikes which contain many maps created by different researchers to show the bike-sharing distribution in a global view (https://bikesharemap.com/; https://citybik.es/; http://www.metrobike.net/). Although the author could not find a map that could illustrate detailed information dynamically, the static maps available provide the necessary quantitative information and general distribution area information

3) Relevant academic literature. Since the rules and manuals for BSSs mostly involve an EU or North American background, they cannot represent the global situation of BSSs. Thus, the author also searched academic databases such as Science Direct and collected papers that introduce BSSs in other areas, such as Asia and Africa.

The following content introduces the development, characteristics, and impact of BSSs, and each section starts with the section summary, followed by brief supporting evidence for the conclusion.

\section{DEVELOPMENT OF BIKE-SHARING SYSTEMS}

Bike-sharing systems have undergone many changes in their development process, including system improvements and equipment upgrading, which can be roughly divided into five categories of activity, as described below.

(1) Bike rental. During the past 50 years, BSSs have changed to the extent that the use range and system structure is very different from their past forms. Staffed station BSSs are also known as bike rental, and considered to be the predecessor of the modern BSS. The system allows people to rent or borrow bikes from and return them to a site. These bike rental systems are more suitable for day-trippers. Some universities rented bikes to students who do not own bikes, and often these sites or rental sites are managed by employees or volunteers. The disadvantage of this system is 
that the return location is the same as the loan location, and this limits the potential usage. However, at the same time, because it directly targets the specific needs of certain people, the staffed station system is still popular in tourism locations, such as hotels, attractions, and railway stations (Geng et al., 2009).

(2) White bikes. Bike-sharing was first attempted in Amsterdam, the Netherlands, in 1965. Some people painted their bikes white and made them freely available to all in Amsterdam (Sache Runde, 2011). The so-called "white bikes" were also called free bikes or first-generation bikes. These bikes were supposed to be left to others after use. However, this was not the case. Within a month, most of the bikes were stolen, and the rest were found in the nearby canal (Shirky, 2008). In some cases, such as college campuses, bikes are designated only for use within a specific area. Upon arrival at the destination, the user should unlock the bike in a public space for other people's use. Since there is no need to return the bike to the hub, the availability of the bike is affected by the number of bikes in the area. Such systems can also suffer from distribution problems, with many of the bikes ending up in remote parts of the city or the mountains. Moreover, because other users may use parked bikes and free bikes at any time, the rider who initially used a bike may face difficulty to find alternative means of transportation for the return trip. This generation of bike-sharing systems has often suffered from theft and vandalism throughout history. After a few years, many plans of the same nature were abandoned (Tozzi, 1997). Most of these systems were based on volunteer work and are supported by the government. Bike repairs and maintenance are completed through volunteer programs or government-contracted operators, but these activities are sometimes conducted by individual users who find defects in free bikes.

(3) Coin deposit BSS. A few years later, the coin deposit BSS, also known as the second-generation BSS, was developed to prevent bikes from being stolen. These bikes are very similar to a bike rental system. People have to put in a certain amount of coins to unlock the bike, and they have to take the bike back to the station and lock it again before they can get their deposits back. Since deposits are only a fraction of the cost of a bike and users are not required to register their information, the system is also vulnerable to theft and vandalism.

(4) Automated station BSS. This type is regarded as the third generation, where bikes can be rented from automated "rental stations" or "docks" and returned to another "rental station" or "dock." The bike is equipped with a bike rack that locks the bike in the station, and can only be released by remote staff or computer control through a cell phone or other means. Users registered within the program can be identified through a specific smart card with their personal information. In many plans for this type of system, the first half-hour ride is generally free. In recent years, many bike-sharing schemes now require users to provide a deposit or other guarantee in order to reduce losses from theft and vandalism. The user is responsible for any damage before the bike is returned to another platform and locked. As of June 2014, this type of bike-sharing system is available in 712 cities in 50 countries/territories across five continents, with about 806,200 bikes operating at 37,500 stations (Shaheen, Susan A et al., 2014). By 2013, there were 650,000 public bikes in China (Shaheen, Susan A., Cohen, \& Martin, 2013). Compared with the first and second-generation systems, the thirdgeneration systems can save on labour costs and reduce vandalism and theft by registering users. However, they require a more significant investment into platforms than the fourth-generation systems need, described below. 
(5) Dockless BBS. This is the fourth generation of BSSs, which was developed around 2000 and is now the most popular type in the world. This system consists of bicycles with locks that are usually attached to the bikes themselves and do not require docking stations or ports. The earliest version of the system included leasable bikes that could be unlocked by calling the seller for a password. The user will then call the supplier a second time to communicate where the bike is parked and locked (Smith, 2009). Recent upgrades to technology and operations over the phone and GPS further enabled the growth of app-controlled dockless bike-sharing systems. The app-controlled bike-share design eliminates the need for users to return their bikes to the station or to call for locking and unlocking. The user can find the nearest available bike through an app (Georgia Institute of Technology, 2010). These systems are prevalent in China, with more than 30 private companies now operating. Among these, Mobike has become the largest bike-sharing operator in the world, with millions of bikes in more than 100 cities (Ye, 2017).

Nevertheless, rapid growth has far outstripped immediate demand, and Chinese cities are overwhelmed with the sudden influx of millions of shared bikes (Fannin, 2017). Since there is no need for supporting platforms or urban planning for infrastructure permission in advance, this system has rapidly become popular worldwide (Shi et al., 2018). On the other hand, these dockless bike-sharing systems are criticised as rogue systems built without respect for local authorities (Sun, 2018).

In many cities, several companies have independently introduced a bikesharing system. However, city officials lack experience in regulating these modes of transportation, and citizens have not developed relevant social habits, causing inconveniences. Currently, regulators have developed different ways of managing such systems by confiscating shared bikes that were not parked correctly in certain areas or issuing new laws to regulate dockless bikes. In the United States, many major metropolitan areas are experimenting with a dockless bike-sharing system. It is reported that, while popular with commuters, the system often receives complaints about illegally parked bikes.

Because of a very challenging start, it took several years for bike-sharing to become well-known. Even in the 1990s, nearly 30 years later, bikesharing systems still accounted for a tiny fraction of a city's public transportation. It was not until the early 21 st century that urban bike-sharing systems became truly popular. The number of BSSs in the world increased from 13 in 2004 to 855 in 2014. As of 2014, the number of bikes available through sharing programs is estimated at 946,000 (Meddin, 2013).

Bike-sharing technology has been around for decades, and system development in Asia is growing exponentially. Of the world's 15 largest bike-sharing schemes, 13 are in China. Since 2012, Wuhan and Hangzhou have been regarded as the most useful bike-sharing systems, with about 90,000 and 60,000 bicycles, respectively (EMBARQ Network, 2017). 


\section{CHARACTERISTICS OF BIKE-SHARING SYSTEMS}

\subsection{Primary users}

From the literature below, people can find that there seem to be different groups of primary users of BSSs across western countries and eastern countries. In many Western countries, BSSs attract a large number of white males who have jobs, are younger, wealthier, and more educated. In Eastern countries such as China, BSSs attract many young people and middle-aged people who have jobs but low financial means. Also, it can be seen that BSSs do not pay much attention to vulnerable groups (such as people with disabilities).

A study in the United States shows that most members of the "Bikesharing Group" are high-income white men, while ethnic minorities, females, low-salary occupants, and those with lower education levels are not (McNeil et al., 2017). However, a study conducted in Beijing shows that its citizens' characteristics seem to be different, and their findings suggest that e-bikes are more prevalent in Beijing than traditional bikes and appeal to a unique demographic: young to middle-aged men, often with lower incomes and education. The trend of increased travel times indicates that e-bikes will attract more office workers for their commutes to and from home. They see e-bike sharing as an appealing choice to short and medium transport trips because of severe traffic congestion and declining quality of public transport services in Beijing. Some studies (Cherry \& Cervero, 2007; Montgomery, 2010; Beijing Transport Institute, 2011) found that certain Chinese urban areas have better portability and running pace for e-bicycles.

Fishman, Washington, and Haworth (2013) used Adelaide city in Australia as their research area, investigating the actual users of the bikesharing program using a network questionnaire survey. The findings indicate that most bicycle-sharing users were less frequent users. Men are more likely than ladies to utilise bicycles. Likewise, these discoveries are comparable with past studies by Fishman and Schepers (2016) and (Goodyear, 2013), both of which concluded that men use bikes at a higher rate.

Another inequality with dockless bike-share systems is where cyclists use their smartphones to find, rent, and lock bikes. A study conducted across several US cities showed that $34 \%$ of low-pay individuals and $13 \%$ of lowsalary whites said they did not have a cell phone (Fillin-Yeh, 2016).

Some of the same distribution characteristics occur in the disabled population. Karki and Tao (2016) investigated the approachability and convenience of a Suzhou bike-sharing program for people who are on the edge of society, with low income and education levels, and irregular work, in an attempt to find solutions to improve the accessibility and quality of services. The results demonstrate that, with low-carbon transport strategies, bike-sharing has turned out to be progressively well applied among rich, college-educated, ordinary labourers, who are male, and the working-age populace, as a result of public policy commitments.

A study in Beijing also showed that bike-sharing is most successful in high-density areas and a few major sightseeing spots. Such zones are situated in urban centres and central business areas, where people can walk, ride bikes or use public transport efficiently (Campbell, A. A. et al., 2016). 


\subsection{Factors affecting consumers' use of BSSs}

As seen in the following research reports and many others (Campbell, A. A. et al., 2016; de Kruijf, Ettema, \& Dijst, 2019; Standage \& Ryan, 2012; Goodyear, 2013), in general, most researchers will find several identical or at least similar factors when studying the motivation behind BSS use. Bikesharing systems will appeal to users in the traditional unsheltered mode for a short period when there is good weather and good air quality. Comparative convenience and economic advantages are the two key factors that influence users' choice of using bikes, while safety issues, including intervention to many other types of vehicles and the absence of committed bicycle infrastructure, are the primary impediments.

Campbell, A. A. et al. (2016) utilised a given inclination study and different logarithms to illustrate the elements that would influence Beijing's shift from existing systems of transportation to bicycles or e-bicycles. They were influenced by different factors: bike users are most sensitive when it comes to effort and satisfaction, while e-bike users are more sensitive to distance, temperature, precipitation, air quality, and other factors. However, while precipitation is likewise a negative factor, the decision to use ebicycles is significantly more tolerant of long distances, high temperatures, and poor air quality. The results of the survey show that environmental conditions and personal travel habits are the main drivers behind cycling intentions, while socio-demographic factors are less critical because BSSs have been shown to appeal to users from different social classes.

A study conducted by de Kruijf, Ettema, and Dijst (2019) in the Netherlands found that satisfaction from travelling by e-bike was higher than satisfaction from commuting by car, with an increase by about 1.4 per cent. This evidence suggests that the shift from cars to electric bikes will significantly increase commuter satisfaction, and thus perhaps overall happiness. Evidence also showed that participants had a high degree of "travel" satisfaction with their e-bike, rather than just a "cycling" experience. Motivation theories of behavioural change, such as Self-determination theory (SDT) (Standage \& Ryan, 2012), assume that if an individual finds a new behaviour more enjoyable, the change in behaviour is more likely to continue. This theory seems to be able to explain the rising level of use of ebikes.

A study in 2017 showed that the New York public bike system is faster for a short trip than with a taxi $(3 \mathrm{~km})$, especially during periods of high congestion such as peak hours during workdays (Faghih-Imani et al., 2017). The same situation occurred near San Francisco's Bayview area, and surveys showed that short-term and non-highway travel was faster and cheaper when using pedal-assisted e-bikes compared to other available modes.

Meanwhile, de Kruijf, Ettema, and Dijst (2019) also showed that factors such as the health condition after physical examination or self-examination, car ownership, degree of urbanisation, whether to use a car, whether ecycling would have to deal with congested roads, traffic congestion, and sense of accomplishment from cycling all affect the level of bike-travel satisfaction. Also, their study found that e-bikes have something similar to traditional bikes in terms of satisfaction. The purpose of the journey can take effect on bicycle travel satisfaction. External factors, such as green and vibrant environment, also contribute to travel satisfaction.

More recently, a study analysed bike-sharing systems in Passo Fundo, a medium-sized city in southern Brazil. Interviews with 526 occupants distinguished three significant reasons for utilising the bike-sharing system: 
health and the environment, social impact, and a cycling habit (Cerutti, Claessens, \& Puy, 2019). The most significant factor was "health and environment," which refers to users' perceptions of their contributions towards reducing traffic and improving the environment and public health. Social impact has shown that the factor motivating people to use BSSs is that they see cycling as a sustainable practice. The study finally found a third factor, the "cycling lifestyle," in which users have sufficient motivation because cycling is part of their lifestyle. They used ANOVA to understand the main reasons for using BSSs and found that users differed in gender, citizenship, education, and income. The main reason for their use of BSSs was that they might help reduce traffic flow. On the other hand, for non-user groups, the primary motivation for not using BSSs is related to lifestyle mismatch.

There was a study conducted that mainly focused on gender differences. Using data from the New York City Bike-sharing System, they investigated the environmental relevance of BSS bike use among males and females. They also studied the impact of bike facilities, land use factors, and public transport services on the proportion of female visitors (Goodyear, 2013). Descriptive statistics show that more than two-thirds of shared-bike trips are done by men, indicating that the use of shared bikes is distorted by gender. However, the estimated values suggest that some variables may affect men and women in different ways. For example, for both genders, the installation of more bike racks is positively related to the bike-sharing use rate, and this factor has a more significant impact on women than men.

Institute for Transportation Development Policy (2013) mentioned that cities that enforce helmet laws face challenges in managing bike-sharing users regarding how to use helmets. As per Australia's compulsory helmet law, a BBS named Seattle's Pronto was shut in mid-2017. They tried to provide free helmets at each bike-sharing station for a while, and helmets offered at little cost. However, the results are minimal because many people believe that this hinders the convenience of bike-sharing. From a maintenance and sanitation point of view, it is a challenge to have every cyclist wear a helmet, requiring extra facilities to store clean helmets at each site. Private bicycle leaders at Pronto's dockless fleet, including LimeBike, have given protective helmets as a promotional action for free and urge riders to comply with laws. The low passenger load of the Melbourne and Brisbane bike-sharing programs is partly due to the helmet laws of these cities.

\subsection{User frequency of BSSs}

When it comes to the use of BSSs, Fishman, Washington, and Haworth (2013) found common use was approximately 3-8 times per bike per day, and this data was confirmed to increase with the instability of traditional public transport systems significantly. Similarly, some other programs, such as London's BCH and Washington, D.C.'s Capital Bikeshare (CaBi), have a usage rate for each bike of three times a day (Fishman, Washington, \& Haworth, 2014). CaBi opened in September 2010 and has more than 2,500 bikes at more than 300 sites (Buehler \& Hamre, 2014). Other projects in the same period were used relatively less frequently. For example, in Australia, each bike was used 0.3-0.4 times per day (Fishman, Washington, \& Haworth, 2013).

Hardt and Bogenberger (2019) included the use of e-scooters in their test and recorded usage through travel diaries while investigating users' attitudes 
toward use through longitudinal surveys. In the pilot study, participants travelled an average of 520.6 kilometres per vehicle, with an average of 23.4 days of activity and an average of 10.6 kilometres of travel. Travel diaries show that these vehicles are used primarily for commuting and spare time travel, even for business travel within the city. Travel analysis and survey results show that both commuter and business travel can be covered with electric scooters, while leisure travellers are also a part. Participants used the provided vehicles in different ways, and about $40 \%$ of users did not use the vehicles again after the end of the test.

\subsection{Purpose of BSSs}

When it comes to government and corporate use, bike-sharing systems are often implemented as part of an overall sustainable transport initiative aimed at reducing pollution, improving travel choices, and achieving other strategic goals.

From Institute for Transportation Development Policy (2013), San Francisco, Mexico City and Pittsburgh's goal of launching a BSS was to solve the first and last-mile traffic problems. This goal is achieved by installing a bike-sharing site near the Caltrain and BART stations. Similarly, the Ecobici of Mexico City was initially designed to enhance the public transport network of the city. The fare structure of the system is similar to that of the public transport system and provides a free 15-minute bike-share ride to the cardholder. As for Paris Vélib' BSS, it was initially adopted as a mechanism to achieve a $25 \%$ greenhouse gas reduction target by 2020 , which is in line with the city's climate-energy plan. In China, the Hangzhou Bike-Sharing System was established and implemented as a means of developing tourism and creating employment opportunities for residents, with funding from the municipal government. The goal in Greater Manchester was to increase the proportion of bike trips of total travel to $10 \%$ and to provide bike-sharing services to help expand bike travel by partnering with dockless operator Mobike.

\section{IMPACT OF THE BIKE-SHARING SYSTEM}

\subsection{Model substitution}

Even though BSSs are intended as a direct "last mile" mode of transport, it is not apparent from the investigations whether they are used this way. More specifically, BSSs could compete with other public transportation travel modes across an entire journey, or at least invite most users to select the unsheltered mode. The impact of this aspect has received more attention, and now, this problem is being studied through several different BSSs. (Soltani et al., 2019)report that the available evidence shows that the rate of replacement from car mode to BSSs is relatively low, indicating that bikesharing is mainly used to supplement walking and other public transportation.

A survey conducted by Shaheen, Susan A et al. (2014) shows that different model shifts happen in different case study cities. The survey found that in the five cities studied, which were Salt Lake City, Minneapolis-St Paul City, Montreal, Toronto, and Mexico City, the number of respondents in four cities commuting by taking buses has decreased. Salt Lake City is the 
only city where bus usage had increased more than before BSSs were introduced. Shaheen, Susan A et al. (2014) believed that the shift in these patterns might be due to differences in public transport networks in the different cities. Montreal and Toronto are big cities with extensive public transport networks.

In contrast, Minneapolis-St Paul and Salt Lake City are relatively small, and their transportation systems are less dense. The most common reason for the reduction in use of other public transportation is that riding a sharing bike provides "faster travel speeds and lower costs." Moreover, the study found that sharing bikes reduced car usage significantly. In Montreal and Toronto, $29 \%$ and $35 \%$ of people said that they drove less, respectively. In St. Paul, Salt Lake City, and Mexico City this statistic was as high as 53\%. In terms of walking, there were more shares in Mexico City. The number of walks in Minneapolis-St. Paul and Salt Lake City increased, while in Montreal and Toronto, most people reported that they are walking less often.

The survey also showed that commuting distance is an essential factor in distinguishing BSS users, and it is also an essential factor in their way of changing travel modes to BSSs (Shaheen, Susan A et al., 2012). In all cities surveyed, the commuting distance of BSS users is usually shorter than that of the general population, but those with relatively long commute times are more likely to increase their use of other public transportation methods.

There is also evidence that BSSs may, in some way, have a lasting and long-term beneficial impact on urban transport, that is, strengthening the cycling model across the longer-term (Institute for Transportation Development Policy, 2013). Since BSSs reduce some of the difficulties related to cycling, they can help to build the number of people riding bikes quickly. Thus, BSSs can be a vital component of a transportation plan, including the long-term vision of cycling habits. For example, in California, Santa Monica passed a bike action plan in 2011 that included bike-sharing as a priority for the city to reduce motor vehicle travel (Institute for Transportation Development Policy, 2013).

Moreover, Dovey (2017) cited the objective of a climate change plan that will promote the scope of bike commuters from $2 \%$ to $6 \%$ by 2020 and $18 \%$ by 2035 . The city has relocated 15 stations which used to serve tourists along the beach to communities in order to make citizens more connected to public transportation and bike infrastructure. Meanwhile, the transportation office committed to building more bike paths and footpaths in downtown San Diego.

In 2012, Rosario in Argentina passed some Municipal Regulations and established the city's public bike system. The Regulations call for "segregated cycle facilities" to connect bike stations and to build these facilities as the system expands. Bike lanes not only benefit bike-sharing users, but all cyclists can use these lanes for a safer, more comfortable ride.

\subsection{Congestion}

A substantial number of studies as described below have shown that BSSs have a positive effect on mitigating the congestion of urban traffic. BSSs can alleviate traffic congestion by directly reducing the number of vehicles. However, the introduction of BSSs has different degrees of impact on cities of different sizes and affluence.

It has been confirmed by Buck et al. (2013) and Shaheen, Susan A., Cohen, and Martin (2013) that BSSs have a direct effect on reducing congestion during rush hour by reducing the use of cars and buses, as people 
choose BSSs instead. Their studies found that the magnitude of the model substitution effect varied from city to city and from region to region.

Wang and Zhou (2017) conducted an empirical study to examine the actual effect of BSSs on urban congestion mitigation. They wanted to study whether the introduction of BSSs can reduce congestion in the city or not. They focused panel data on 96 urban areas in the United States from 2005 to 2014. The results show that, generally, the impact of the introduction of BSSs on congestion presents a significantly mixed effect: the situation in larger cities is better than in other cities, but the situation in wealthier cities is worse. In terms of reducing congestion, BSSs benefit big cities more than small cities. This finding is consistent with past research illustrating that BSSs have reduced the use of private vehicles and taxis in almost every city (Martin \& Shaheen, 2014; Shaheen, Susan A., Cohen, \& Martin, 2013), which found that under other covariates, for every $1 \%$ increase in urban population without BSSs, traffic congestion increases by $0.6863 \%$. However, for every $1 \%$ increase in urban population with BSSs, traffic congestion decreases by $0.0264 \%$.

Another study attempts to explain why BSSs in wealthy cities have not been very effective in alleviating congestion, and it pointed out that promoting BSSs sometimes promotes more travel (Ahillen, Mateo-Babiano, \& Corcoran, 2016). In wealthier cities, where more people own private cars, people tend to use private cars for these extra "travel plans."

Many studies indicate that BSSs either directly reduce vehicle use (DeMaio, 2009; Martin \& Shaheen, 2014), or indirectly improve the use of public transport by linking the last miles (Fishman, Washington, \& Haworth, 2013; Noland \& Ishaque, 2006; Shaheen, Susan A., Cohen, \& Martin, 2013). Recently, Campbell, K. B. and Brakewood (2017) found that after controlling the development of cycle paths, every 1,000 BSS stops on a bus route reduced the daily unlinked bus trips on the roads of New York City by $1.69 \%$. Also, according to the national family travel survey (Federal Highway Administration (FHWA), 2009), 37.6\% of private cars and 73.6\% of bikes travel less than 2 miles, which means that BSSs have room to increase the transition from private cars to BSSs.

\subsection{Health/Safety impact}

The health benefits of BSSs are apparent from two aspects: Firstly, traffic congestion can be alleviated, and thus air quality can be improved by reducing the use of private cars. Secondly, riding bikes is a form of exercise, which improves people's health. Particulate matter in vehicle exhausts is associated with severe respiratory health problems, with higher concentrations of particulate matter existing near busy roads. BSSs offer an alternative to car travel, and this can help reduce local traffic. A study of the Washington Metropolitan bike-sharing system found that using these systems in the region could reduce traffic congestion by $4 \%$. Minimising traffic congestion means reducing air pollution, which is beneficial not only to cyclists but also to all other urban populations as well (Hamilton \& Wichman, 2018).

Moreover, de Kruijf, Ettema, and Dijst (2019) noted that while e-bike technology is superior to conventional bikes when it comes to speed and radius of action, e-cyclists still need to perform a lot of physical movements (Simons, Van Es, \& Hendriksen, 2009) which could improve health and reduce the chances of developing a disease linked to sedentary lifestyle (de Geus et al., 2013). 
Helmet laws have also raised concerns about cycling safety. However, it has been reported that bike crash statistics show that sharing bikes could be safer than traditional cycling. This phenomenon may be due to the considerable weight of the shared bike, the presence of reflectors and lights, the low centre of gravity of the bike, and the gear ratio, which usually prevents the cyclist from moving at high speeds. Dallas, Texas, is currently planning a BSS project, but due to the poor performance of bike programs subject to such regulations, the city recently withdrew its enforced helmet law (Fishman et al., 2014). In other cities with mandatory laws, such as Seattle and Vancouver, further development of the helmet distribution system may increase the use of helmets and may increase the number of people riding bikes (Gutman, 2016).

\subsection{Environmental impact}

Unfortunately, there is not enough evidence to show that BSSs have a positive impact on the urban environment or air quality specifically. In contrast, there is even evidence that BSSs harm the environment of a city.

Many commentators who support BSSs have estimated the $\mathrm{CO}_{2}$ emissions saved by shared bikes and have concluded that BSSs have a positive impact on the environment (Siegle, 2017). However, these results are questionable because they are usually not validated using data or user surveys, but rather with the null hypothesis that shared bike travel can fully replace car travel. As described in the "Model Substitution" section, so far, in the cases of public bike trips replacing other modes of transport, private car trips have not been replaced at a high proportion. In contrast, bike trips have replaced other public transport or walking in many cases.

Zhang and Mi (2018) experimented by using big data technology. The environmental benefits of BSSs in Shanghai were evaluated from the perspective of space and time. They found that, in 2016, Shanghai BSSs saved 8,358 tons of gasoline, 25,240 tons of carbon dioxide, and 64 tons of nitrogen oxide emissions. However, there are several limitations to this experiment. Firstly, due to privacy issues, the shared bike data they gathered was pre-processed by Mobike Company. Secondly, they only used data from a single bike-sharing company. In addition, the increased emissions of pollutants and energy use in bike production and redistribution processes that result from the bike-sharing industry were not taken into account.

One investigation sought to make a more straightforward analysis of the ecological benefits of bike-sharing using BSS data in London (UK), Melbourne and Brisbane (Australia), Washington, DC, and Minnesota. Fishman, Washington, and Haworth (2014) studied the net change from vehicle to shared bike use by observing the replacement rate, which also included travel distances for vehicles used for bike redistribution and maintenance. The results of the study showed that bike-sharing could increase, rather than reduce, the overall use of vehicles due to the impact of bike maintenance and redistribution in the researched cities. More specifically, in London, one kilometre of shared bike travel would generate $2.2 \mathrm{~km}$ of car travel by redistribution trucks, which is an overall negative for the environment. 


\subsection{Economic impact}

Few studies have focused on the economic impact of BSSs. Generally speaking, many BSSs are not profitable when they are initially set up, because the rent is very cheap and some even free, while the equipment including bikes, GPS and electronic locks are costly. In other words, most BSSs will not have any direct economic benefit in the first few years, which perhaps is the reason that most research only studies the indirect economic benefits. The authors found several related studies through literature review. Bullock, Brereton, and Bailey (2017) and his team found that time-saving is the most significant economic impact. Through survey studies, they found that BSSs can reduce the time spent on travel by promoting connectivity between cities. The saved time can be better used to produce economic value. This conclusion is supported by the research of (Buehler \& Hamre, 2014) and Börjesson and Eliasson (2012). Moreover, Bullock, Brereton, and Bailey (2017) found that the car accidents in Dublin were reduced due to the introduction of BSSs. They estimated that the reduction of car accidents through BSSs' utilisation reduced citizens' and the government's spending by about 30,240 euros per year. In addition, they found that the fitness of citizens who use bike-sharing has improved. They used a hypothetical model and estimated that BSSs could reduce the cost of health care for Dublin citizens by 206,000 to 412,000 euros per year. This conclusion is very similar to that of Woodcock et al. (2014).

\section{DISCUSSION AND CONCLUSION}

In general, this article has reviewed the development, characteristics, and impact of BSSs by collecting and analysing existing academic literature and official reports. With the development of science and technology and the advancement of the times, BSSs have undergone significant changes at both the system structural level and the quantitative level. The characteristics of BSSs are reflected in different aspects. Users in the western world, especially in Europe and the United States, are usually men, younger, and above-average socioeconomic status, while in Asia, Chinese users are primarily young-to-middle-aged men, often with lower incomes and education. Among the factors that will affect BSSs, comparative convenience and economic advantages are the two key factors that influence users' choice of using bikes, while safety issues and the absence of committed bicycle infrastructure, are the primary impediments. Generally, a public bicycle is used 3-8 times a day. Furthermore, different governments introduce BSSs for different purposes, either to reduce traffic congestion, to improve urban public transportation systems, or to reduce greenhouse gas emissions.

The impact of BSSs on society is mostly positive, but some have not met expectations. For instance, in terms of the impact of model substitution, BSSs will replace vehicle travel as well as walks. However, its impact on reducing private car use is limited, because more users have shifted from buses rather than from private cars. BSSs play a significant role in alleviating traffic congestion by reducing the number of vehicles on the road. After this reduction of traffic congestion, the degree of air pollution on the roadside has also been alleviated, so pedestrians who go out are less vulnerable to adverse health impacts. At the same time, BSSs are considered 
safer than other bicycles because of their lower centre of gravity. Environmental impact is one of the fundamental goals of BSS implementation, but their ability to reduce carbon emissions is still questioned.

This article reviews the development process of BSSs through a large number of documents and websites. At the same time, it summarises research results related to the characteristics of BSSs across various aspects, as well as its impact on society. The authors hope that this review article will be convenient for those who are trying to research the field of BSSs in the future. Meanwhile, from the authors' perspective, future studies into BSSs should focus more on environmental impact since this was a fundamental factor when the bike-sharing system was created. Few studies have thoroughly calculated what emissions are generated from the production of shared bikes, the use of BSSs, redistribution by trucks, and finally being discarded or recycled, and what the total reduction is from switching from private to bicycle emissions. For current cities, whether existing BSSs increase or reduce the burden on the environment is a point that governments and researchers need to pay attention to in the future. Additionally, the author also found that few studies have compared the resources and space required between the traditional rental bike system and the modern bikesharing system. The author believes that this comparative study is also significant. Through various comparisons, the government can efficiently choose different types of systems for different needs.

\section{REFERENCES}

Ahillen, M., Mateo-Babiano, D., \& Corcoran, J. (2016). "Dynamics of Bike Sharing in Washington, Dc and Brisbane, Australia: Implications for Policy and Planning". International Journal of Sustainable Transportation, 10(5), 441-454. doi: https://doi.org/10.1080/15568318.2014.966933.

Beijing Transport Institute. (2011). 2011 Beijing Transport Annual Report. Beijing Transport Institute. Retrieved from http://www.bjtrc.org.cn/Show/download/id/1/at/0.html.

Börjesson, M., \& Eliasson, J. (2012). "The Value of Time and External Benefits in Bicycle Appraisal". Transportation Research Part A: Policy and Practice, 46(4), 673-683. doi: https://doi.org/10.1016/j.tra.2012.01.006.

Buck, D., Buehler, R., Happ, P., Rawls, B., Chung, P., \& Borecki, N. (2013). "Are Bikeshare Users Different from Regular Cyclists?:A First Look at Short-Term Users, Annual Members, and Area Cyclists in the Washington, D.C., Region". Transportation research record, 2387(1), 112-119. doi: https://doi.org/10.3141/2387-13.

Buehler, R., \& Hamre, A. (2014). "Economic Benefits of Capital Bikeshare: A Focus on Users and Businesses". Virginia Tech, Urban Affairs and Planning, Alexandria Center. Retrieved from https://rosap.ntl.bts.gov/view/dot/27421.

Bullock, C., Brereton, F., \& Bailey, S. (2017). "The Economic Contribution of Public BikeShare to the Sustainability and Efficient Functioning of Cities". Sustainable Cities and Society, 28, 76-87. doi: https://doi.org/10.1016/j.scs.2016.08.024.

Campbell, A. A., Cherry, C. R., Ryerson, M. S., \& Yang, X. (2016). "Factors Influencing the Choice of Shared Bicycles and Shared Electric Bikes in Beijing". Transportation Research Part C: Emerging Technologies, 67, 399-414. doi: https://doi.org/10.1016/j.trc.2016.03.004.

Campbell, K. B., \& Brakewood, C. (2017). "Sharing Riders: How Bikesharing Impacts Bus Ridership in New York City". Transportation Research Part A: Policy and Practice, 100, 264-282. doi: https://doi.org/10.1016/j.tra.2017.04.017.

Cerutti, E., Claessens, S., \& Puy, D. (2019). "Push Factors and Capital Flows to Emerging Markets: Why Knowing Your Lender Matters More Than Fundamentals". Journal of international economics, 119, 133-149. doi: https://doi.org/10.1016/j.jinteco.2019.04.006.

Chen, M. (2016, 09/01). "Hangzhou Abuzz over Bike Sharing". China Daily. Retrieved from http://www.chinadaily.com.cn/business/2016hangzhoug20/2016-

09/01/content_26665873.htm. 
Cherry, C., \& Cervero, R. (2007). "Use Characteristics and Mode Choice Behavior of Electric Bike Users in China". Transport Policy, 14(3), 247-257. doi: https://doi.org/10.1016/j.tranpol.2007.02.005.

de Geus, B., Kempenaers, F., Lataire, P., \& Meeusen, R. (2013). "Influence of Electrically Assisted Cycling on Physiological Parameters in Untrained Subjects". European Journal of Sport Science, 13(3), 290-294. doi: https://doi.org/10.1080/17461391.2011.606845.

de Kruijf, J., Ettema, D., \& Dijst, M. (2019). "A Longitudinal Evaluation of Satisfaction with E-Cycling in Daily Commuting in the Netherlands". Travel Behaviour and Society, 16, 192-200. doi: https://doi.org/10.1016/j.tbs.2018.04.003.

DeMaio, P. (2009). "Bike-Sharing: History, Impacts, Models of Provision, and Future". Journal of Public Transportation, 12(4), 41-56. doi: http://doi.org/10.5038/23750901.12.4.3.

Dovey, R. (2017, 09/07). "San Diego Aims to Shift Bike-Share Focus from Tourists to Commuters". Next City. Retrieved from https://nextcity.org/daily/entry/san-diego-shiftbike-share-focus-tourists-to-commuters.

EMBARQ Network. (2017). "From Amsterdam to Beijing: The Global Evolution of Bike Share". Retrieved from https://www.smartcitiesdive.com/ex/sustainablecitiescollective/amsterdam-beijing-globalevolution-bike-share/1100421/.

Faghih-Imani, A., Anowar, S., Miller, E. J., \& Eluru, N. (2017). "Hail a Cab or Ride a Bike? A Travel Time Comparison of Taxi and Bicycle-Sharing Systems in New York City". Transportation Research Part A: Policy and Practice, 101, 11-21. doi: https://doi.org/10.1016/j.tra.2017.05.006.

Fannin, R. (2017, 03/28). "Bike Sharing Apps in China Pop up as Latest Startup and Unicorn Craze". $\quad$ Forbes. Retrieved from https://www.forbes.com/sites/rebeccafannin/2017/03/28/bike-sharing-apps-in-china-popup-as-latest-startup-and-unicorn-craze/\#63d3cfe71bcc.

Federal Highway Administration (FHWA). (2009). 2009 National Household Travel Survey. U.S. Department of Transportation. Federal Highway Administration (FHWA).

Fillin-Yeh, K. (2016, April 26). "How We'll Know When We're Getting Bike Equity Right". Next City. Retrieved from https://nextcity.org/daily/entry/bike-share-equity-metricsdiverse-riders.

Fishman, E., \& Schepers, P. (2016). "Global Bike Share: What the Data Tells Us About Road Safety". Journal of Safety Research, 56, 41-45. doi: https://doi.org/10.1016/j.jsr.2015.11.007.

Fishman, E., Washington, S., \& Haworth, N. (2013). "Bike Share: A Synthesis of the Literature". Transport Reviews, 33(2), 148-165. doi: https://doi.org/10.1080/01441647.2013.775612.

Fishman, E., Washington, S., \& Haworth, N. (2014). "Bike Share's Impact on Car Use: Evidence from the United States, Great Britain, and Australia". Transportation Research Part D: Transport and Environment, 31, 13-20. doi: https://doi.org/10.1016/j.trd.2014.05.013.

Fishman, E., Washington, S., Haworth, N., \& Mazzei, A. (2014). "Barriers to Bikesharing: An Analysis from Melbourne and Brisbane". Journal of Transport Geography, 41, 325337. doi: https://doi.org/10.1016/j.jtrangeo.2014.08.005.

Geng, X., Tian, K., Zhang, Y., \& Li, Q. (2009). "Bike Rental Station Planning and Design in Paris". Urban Transport of China, 7(4), 21-29.

Georgia Institute of Technology. (2010, June 10). "Scientists Strive to Replace Silicon with Graphene on Nanocircuitry". Retrieved from https://www.news.gatech.edu/2010/06/09/scientists-strive-replace-silicon-graphenenanocircuitry.

Goodyear, S. (2013, 08/19). "Bike-Share Is Key to Closing the Cycling Gender Gap". The Atlantic Monthly. Retrieved from http://www.theatlanticcities.com/commute/2013/08/bike-share-may-be-one-keyclosingcycling-gender-gap/6580.

Gutman, D. (2016, Dec 19). "Will Helmet Law Kill Seattle's New Bike-Share Program?". The Seattle Times. Retrieved from https://www.seattletimes.com/seattlenews/transportation/will-helmet-law-kill-seattles-new-bike-share-program/.

Hamilton, T. L., \& Wichman, C. J. (2018). "Bicycle Infrastructure and Traffic Congestion: Evidence from Dc's Capital Bikeshare". Journal of Environmental Economics and Management, 87, 72-93. doi: https://doi.org/10.1016/j.jeem.2017.03.007.

Hardt, C., \& Bogenberger, K. (2019). "Usage of E-Scooters in Urban Environments". Transportation Research Procedia, 37, 155-162. doi: https://doi.org/10.1016/j.trpro.2018.12.178. 
Institute for Transportation Development Policy. (2013). The Bike-Share Planning Guide. ITDP Institute for Planning \& Development Policy. Retrieved from http://bikeshare.itdp.org/guide/introduction/.

Karki, T. K., \& Tao, L. (2016). "How Accessible and Convenient Are the Public Bicycle Sharing Programs in China? Experiences from Suzhou City". Habitat International, 53, 188-194. doi: https://doi.org/10.1016/j.habitatint.2015.11.007.

Martin, E. W., \& Shaheen, S. A. (2014). "Evaluating Public Transit Modal Shift Dynamics in Response to Bikesharing: A Tale of Two U.S. Cities". Journal of Transport Geography, 41, 315-324. doi: https://doi.org/10.1016/j.jtrangeo.2014.06.026.

McNeil, N., Dill, J., MacArthur, J., Broach, J., \& Howland, S. (2017). Breaking Barriers to Bike Share: Insights from Residents of Traditionally Underserved Neighborhoods. (Vol. NITC-RR-884b). Portland, OR: Transportation Research and Education Center (TREC). doi: https://doi.org/10.15760/trec.176.

Meddin, R. (2013, 04/19). "The Bike-Sharing World Map". The Bike-Sharing Blog. Retrieved from http://bike-sharing.blogspot.com/2013/04/.

Montgomery, B. N. (2010). "Cycling Trends and Fate in the Face of Bus Rapid Transit: Case Study of Jinan, Shandong Province, China". Transportation research record, 2193(1), 28 36. doi: https://doi.org/10.3141/2193-04.

Noland, R. B., \& Ishaque, M. M. (2006). "Smart Bicycles in an Urban Area: Evaluation of a Pilot Scheme in London". Journal of Public Transportation, 9(5), 71-95. doi: http://doi.org/10.5038/2375-0901.9.5.5.

OBIS (Optimising Bike Sharing in European Cities) (2011). "Optimizing Bike Sharing in European Cities: A Handbook". Intelligent Energy Europe. Retrieved from http://ec.europa.eu/energy/intelligent/projects/sites/ieeprojects/files/projects/documents/obis handbook en.pdf.

Sache Runde. (2011, 06/11). "Readers Digest Deutschland (in German) ", pp. 74-75.

Shaheen, S. A., Cohen, A. P., \& Martin, E. W. (2013). "Public Bikesharing in North America: Early Operator Understanding and Emerging Trends". Transportation research record, 2387(1), 83-92. doi: https://doi.org/10.3141/2387-10.

Shaheen, S. A., Martin, E. W., Cohen, A. P., Chan, N. D., \& Pogodzinski, M. (2014). "Public Bikesharing in North America During a Period of Rapid Expansion: Understanding Business Models, Industry Trends \& User Impacts, Mti Report 12-29". Mineta Transportation Institute Publications.

Shaheen, S. A., Martin, E. W., Cohen, A. P., \& Finson, R. S. (2012). "Public Bikesharing in North America: Early Operator and User Understanding". Mineta Transportation Institute. Retrieved from https://rosap.ntl.bts.gov/view/dot/24566.

Shi, J.-g., Si, H., Wu, G., Su, Y., \& Lan, J. (2018). "Critical Factors to Achieve Dockless Bike-Sharing Sustainability in China: A Stakeholder-Oriented Network Perspective". Sustainability, 10(6), 2090. doi: https://doi.org/10.3390/su10062090.

Shirky, C. (2008). Here Comes Everybody: The Power of Organizing without Organizations. New York: Penguin.

Siegle, L. (2017, April 16). "The Eco Guide to Bike-Sharing". Guardian US. Retrieved from https://www.theguardian.com/environment/2017/apr/16/the-eco-guide-to-bike-sharing.

Simons, M., Van Es, E., \& Hendriksen, I. (2009). "Electrically Assisted Cycling: A New Mode for Meeting Physical Activity Guidelines". Medicine \& Science in Sports \& Exercise, 41(11), 2097-2102. doi: https://doi.org/10.1249/MSS.0b013e3181a6aaa4.

Smith, D. (2009). "Bike Sharing Gets an Electric Update - New Electric Bike Concept Could Fill Transit Gaps". Retrieved from https://www.popsci.com/scitech/article/2009-06/bikesharing-gets-electric-update/.

Soltani, A., Allan, A., Anh Nguyen, H., \& Berry, S. (2019). "Bikesharing Experience in the City of Adelaide: Insight from a Preliminary Study". Case Studies on Transport Policy, 7(2), 250-260. doi: https://doi.org/10.1016/j.cstp.2019.01.001.

Standage, M., \& Ryan, R. M. (2012). "Self-Determination Theory and Exercise Motivation: Facilitating Self-Regulatory Processes to Support and Maintain Health and Well-Being". Advances in Motivation in Sport and Exercise, 3rd Edition (pp. 233-270): Human Kinetics.

Sun, Y. (2018). "Sharing and Riding: How the Dockless Bike Sharing Scheme in China Shapes the City". Urban Science, 2(3), 68. doi: https://doi.org/10.3390/urbansci2030068

Tozzi, L. (1997, 10/17). "Ride on, Yellow Bikes". The Austin Chronicle. Retrieved from https://www.austinchronicle.com/news/1997-10-17/518610/.

Wang, M., \& Zhou, X. (2017). "Bike-Sharing Systems and Congestion: Evidence from Us Cities". Journal of Transport Geography, 65, 147-154. doi: https://doi.org/10.1016/j.jtrangeo.2017.10.022. 
Woodcock, J., Tainio, M., Cheshire, J., O’Brien, O., \& Goodman, A. (2014). "Health Effects of the London Bicycle Sharing System: Health Impact Modelling Study". BMJ : British Medical Journal, 348, g425. doi: https://doi.org/10.1136/bmj.g425.

Ye, J. (2017, April 9). "Why China's Bike-Sharing Boom Is Causing Headaches". South China Morning Post. Retrieved from https://www.scmp.com/news/china/society/article/2085751/chinas-bike-sharing-boomputs-pressure-planners.

Zhang, Y., \& Mi, Z. (2018). "Environmental Benefits of Bike Sharing: A Big Data-Based Analysis". Applied energy, 220, 296-301. doi: https://doi.org/10.1016/j.apenergy.2018.03.101. 